\title{
Using suitability analysis, informed by Co-Design, to assess contextually appropriate urban growth models in Gulu, Uganda
}

\author{
Julian Bolleter (D) ${ }^{a}$, Richard Vokes $\mathbb{D}^{\mathrm{b}}$, Anthony Duckworth (1D), Grace Oliver ${ }^{\mathrm{a}}$, \\ Tony McBurney ${ }^{c}$ and Paula Hooper $\left(\mathbb{D}^{a}\right.$
}

${ }^{a}$ Australian Urban Design Research Centre, University of Western Australia, Perth, Australia; ${ }^{\text {bDiscipline of }}$ Anthropology and Sociology, University of Western Australia, Perth, Australia; Integrated Design Group Pty Ltd, Bathurst, Australia

\begin{abstract}
Uganda has one of Africa's fastest urban growth rates, compounding urban challenges, including urban sprawl, the proliferation of informal settlements, decrepit housing, and the privatization of urban development without providing public open space and transport connectivity. In response, this paper tests generic models of urbanization that could be applied in Uganda. This evaluation is conducted through a suitability analysis, informed through CoDesign activities, of the city of Gulu in Northern Uganda. The paper concludes that a corridor model is most responsive to existing environmental, transportation and land-use conditions and residents' aspirations.
\end{abstract}

\section{KEYWORDS}

African urbanization; Uganda; suitability analysis; co-design; Gulu

\section{Introduction}

A legacy of approaches to 'town planning' established in many African states ${ }^{1}$ in the colonial era and continued throughout the Cold War saw European urbanization models imposed on African polities. This situation often resulted in pre-existing, traditional urban life models being frequently ignored and destroyed. Colonial-era planning laws continue to frame legislative environments in many contemporary African countries (Wekwete 1995).

Moreover, since the end of the Cold War, which coincided with International Monetary Fund-led structural-adjustment programmes, has witnessed general deregulation and 'opening up' of many African economies, which has seen rapid economic growth across large parts of the continent. This growth has stimulated huge new demand - especially from Africa's new entrepreneurs and from the continent's rising 'middle classes' in general - for new kinds of urban commercial and residential property and expanded leisure facilities.

Nevertheless, deregulation itself frequently hollowed out planning departments, and in other ways weakened the governance capacity of many African countries to manage, or even to oversee, these new demands. Even today, many African countries continue to 
struggle with the fragmented institutional landscapes for planning that structuraladjustment created. See, for example, Goodfellow's study of its ongoing legacy for urban planning in Uganda's capital, Kampala (Goodfellow 2010).

For many African countries, the period of post-1989 growth has also witnessed rising inequality, which in turn resulted in international development interventions being, for a long time, primarily focused upon the socioeconomic determinants of deprivation for example, health, education, gender empowerment - rather than upon the built environment. Indeed, it is only relatively recently that development agendas have begun to move away from this 'anti-poverty agenda' (Hickey 2013). In this context, the problematics of 'urban development' tended to be similarly framed in terms of the issues and problems faced by the lowest socioeconomic stratum of city residents - i.e., slum dwellers - rather than by any more holistic challenges of urban design (Muchadenyika and Waiswa 2018).

The combined effect has been that many African governments were effectively forced to adopt new 'urban master plans', from roughly 2010 onwards - in response to their accelerating urbanization and the demands of the new economy and its nouveau riche. These were more often than not designed and implemented, not by African institutions and companies, but by international commercial agencies (Vokes 2019; Watson 2014). Much of current African property investment has been inspired by Asian or Middle Eastern examples (Bolleter 2019; Bolleter and Cameron 2021) in which entirely new cities are built on the periphery of existing cities (Van Noorloos and Kloosterboer 2017, 2). These 'world-class cities' - the plans for which often resemble existing centres of global capitalism - Dubai, Hong Kong, or Shanghai (Vokes 2019, 307) - bring together aspirations for economic growth, attracting Foreign Direct Investment and a growing middle class, and providing an escape from the disorder and suffering of existing cities (Mutuku, Boerboom, and Madureira 2019, 293). Nonetheless, van Noorloos et al. warn us that these private communities for the wealthy will be, at best, 'unsuitable for solving Africa's urban problems. At worst, they will increase expulsions of the poor, as well as public funding injustice and sociospatial segregation and fragmentation' (Van Noorloos and Kloosterboer 2017, 1) - much as they have elsewhere globally. They will be, in other words, fundamentally exclusionary (cf. de Boeck 2011). Moreover, these models more closely replicate those followed by Asian 'tiger' states, which tend to be more top-down or 'paternalistic' models (Knebel 2012, 2).

This situation may also reflect the wider shift away from the anti-poverty approach towards a new kind of more ambitious development agenda, based upon further structural transformation - to achieve even more rapid economic growth. In this regard, it is relevant that the new urban master plans usually also articulate with broader national development plans, which are invariably framed in terms of some spectacular 'vision' of that country's future goals, for example, Vision 2020 (Rwanda), Vision 2030 (Mauritius), Émergence 2030 (Madagascar), Vision 2030 (Kenya), Vision 2040 (Uganda), Vision 2050 (the East African Community).

There is a need for urbanization models, global or otherwise, which respond to local environmental, transportation and land-use factors, yet remain attentive to the needs of diverse urban populations and those expressed by civil society. This article aims to forward this agenda by considering what a more case-sensitive model of urbanization might look like for Gulu, Uganda - a rapidly expanding city which is reflective of many African urban planning challenges. Firstly, a unique locally focussed Co-Design approach, 
combined with a suitability analysis, is conducted to assess generic models of urbanization (Forman 2010) for their applicability in Gulu's environmental, infrastructural, societal, cultural and economic context.

The paper is structured in the following way. A snapshot of historic and current urbanization trends in Uganda and Gulu is provided in the background section. The potential of suitability analyses to underpin urban models is also scoped. In the subsequent methods section, engagement with local actors through Co-Design is described, and the related factors emerging from this and underpinning the suitability analysis are set out in detail. In the results section, the optimal areas for urbanization, identified in the suitability analysis, are mapped. These generally accord with the urban corridor model. In the discussion section, the benefits of the corridor model of urbanization for Gulu are discussed, and a sketch plan for Gulu's expansion is tabled - and consideration is given to how this be made responsive to residents' lived experience of the city (especially their urban livelihoods), and to their expressed aspirations for the future city. Finally, the paper concludes by summating the findings and scoping the implications of the research.

\section{Background}

\section{Urbanization in Uganda}

A large proportion of the world's rapid urbanization is occurring in Africa, where the urban population will effectively triple in the next three decades, with more than 1.3 billion Africans living in cities by 2050 (Van Noorloos and Kloosterboer 2017, 2).

Uganda has a population base of 35 million and a substantial growth rate of $3.2 \%$, one of the fastest in Africa (United Nations Habitat, and Ministry of Lands Housing and Urban Development 2016, 2). Though Uganda still has a low level of urbanization (18.2\%), it has a high urban growth rate of 5.2\% per year. This growth rate has significant implications in terms of needs for housing, water, health, education, jobs and urban services (United Nations Habitat, and Ministry of Lands Housing and Urban Development 2016, 2). Indeed, urban challenges include limited coverage of essential infrastructure services, including water, energy, and sanitation (United Nations Habitat, and Ministry of Lands Housing and Urban Development 2016, viii), a sprawling of major centres, a youth bulge in urban areas, proliferation of informal settlements, decrepit housing, and the privatization of urban development without providing public open space and transport connectivity (Goodfellow 2010).

The highest-level policy document relating to cities in Uganda is the Vision 2040 National Development Plan, launched in 2013. This plan outlines a vision for Uganda to achieve middle-income status by providing transport and energy infrastructure, manufacturing, and Information and Communication Technologies. The Vision 2040 document casts the development of the country's new cities - which are otherwise growing quickly because of demographic pressures - as crucial for attaining all of these goals. The type of city expansion proposed in Vision 2040 - for both Kampala and Uganda's new cities, such as Gulu, is characterized as what could be described as the country's 'third wave' of urban development. This contemporary development follows the first wave, which occurred as part of the colonization process from the 1890s, and into the first decades of the twentieth century (Terreni Brown 2013), and the second, which occurred as part of post-WWII 
'modernization' programmes. The latter began in the early-1950s and reached its zenith in the Kampala Master Plan of 1972 (which was the culmination of work done by three separate UN Planning Missions, in 1963, 1964, and 1967-8, respectively; (Omolo-Okalebo 2011, 97-147).

\section{Urbanization in Gulu}

The town of Gulu itself was created in the first wave of urban development and was planned by, and for, the British Protectorate in the heart of East Africa. Gulu was established in the early twentieth century as the 'last civilized outpost' at the head of a rail link directly from the port in Mombasa on the coast, deep into the productive lands of northern Uganda and with access to minerals and resources from Sudan and the Congo (Figure 1). The town was planned and purposeful. The plan's robustness has enabled it to adapt over time from a 'quartered' settlement, in which populations were segregated along racial lines, with separate residential quarters for European administrators, Indian traders, and African residents. This model for urban design in British colonial Africa traces ultimately to the British Raj, where it was understood that residential segregation was the most effective method for protecting the colonists' health (Omolo-Okalebo 2011, 32-34).

It is beyond the scope here to provide an exhaustive history of Gulu's development. However, it is necessary to note some of its more recent histories. Specifically, following Uganda's national civil war (1981-1986), much of Northern Uganda experienced major

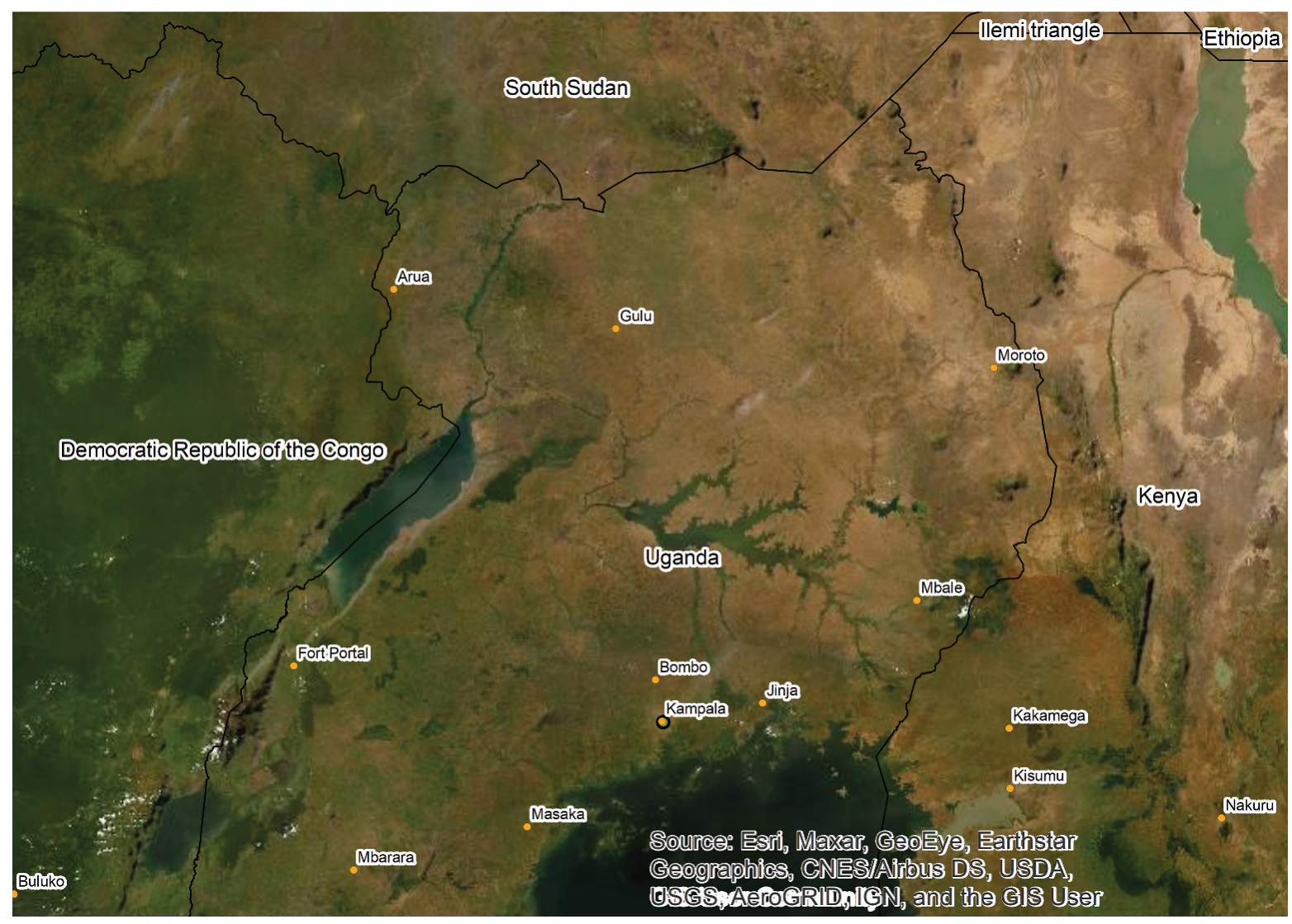

Figure 1. Gulu location map. 
insecurity and widespread political violence. In particular, between 1987 and 2006, the region was the primary arena for the Lord's Resistance Army insurgency. Much of the Lord's Resistance Army was focused on Gulu's rural hinterlands. As a result, throughout the period, the municipality itself was an island of relative security amid the violence that wracked the rest of Acholiland. ${ }^{2}$ Insecurity in the countryside caused many people to relocate to urban areas for protection (Branch 2011, 1). This factor explains why the Gulu municipality was among the largest urban areas in Uganda in the 2002 census (United Nations Habitat, and Ministry of Lands Housing and Urban Development 2016, 4). Although a centre of internal displacement, with over 130,000 people crowded into a space meant for a quarter of that number, the town remained mostly isolated from the countryside's massive devastation (Branch 2011, 1). Insurgency and counter-insurgency operations resulted in widespread displacement across the largely rural western part of Acholiland, which affected hundreds of thousands of people (Branch 2011, 2).

A minor town that had comprised of a few paved streets surrounded by dispersed houses was thus inundated by dense clusters of recently constructed grass-thatched mud huts constructed by the displaced people (Figures 2 and 3).

From 1996 onwards, Gulu was effectively one huge camp, home to the largest population of internally displaced persons in the region, ultimately housing an increased population of about 90,000. Devoid of significant agriculture or industry, Gulu established

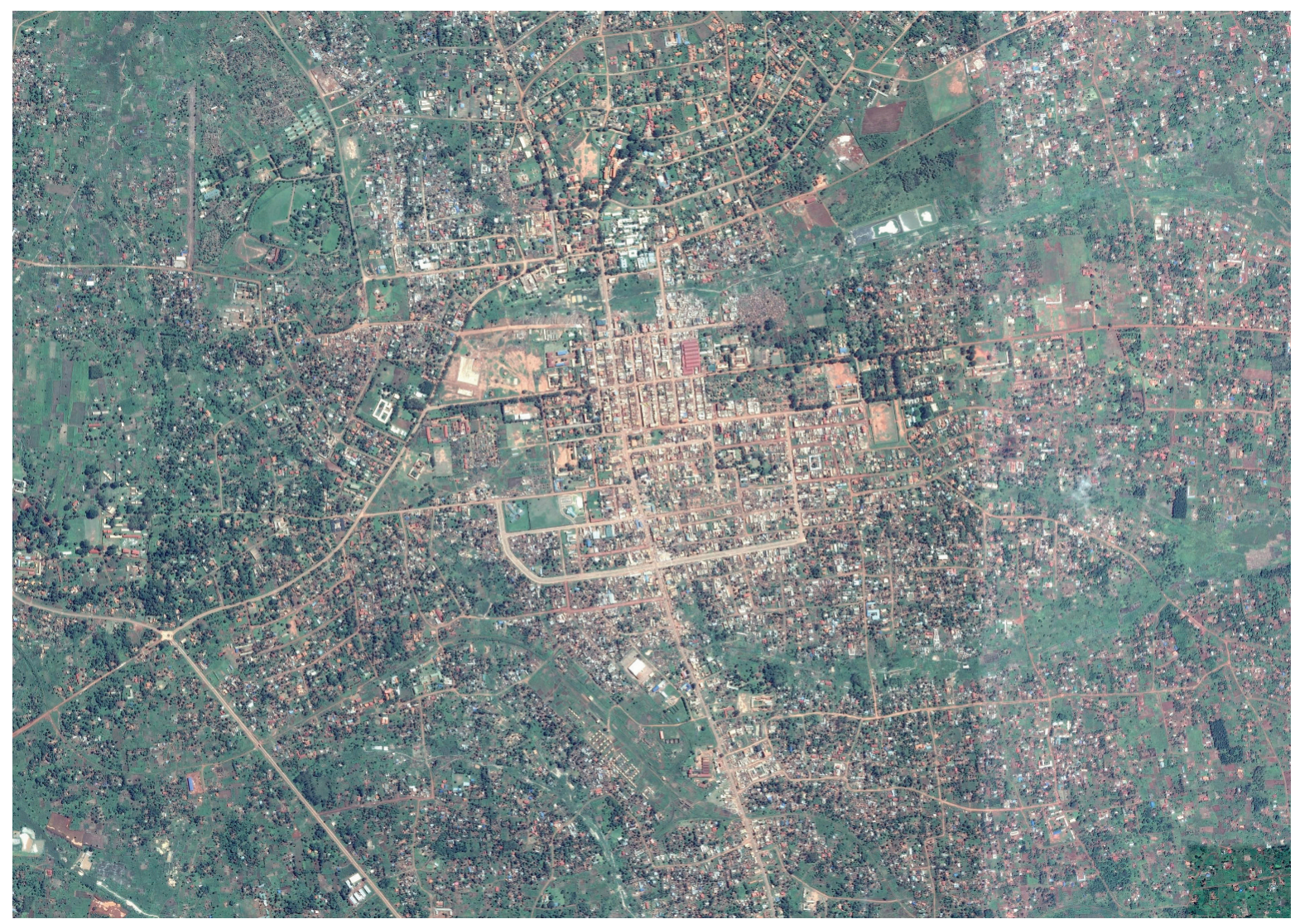

Figure 2. A contemporary aerial photo of Gulu's core area consists of unpaved roads and one to two storey makeshift buildings. As yet largely undeveloped, a system of wetlands exists to the north and south of the urban core. Image courtesy of Google Earth/ Maxar Technologies. 


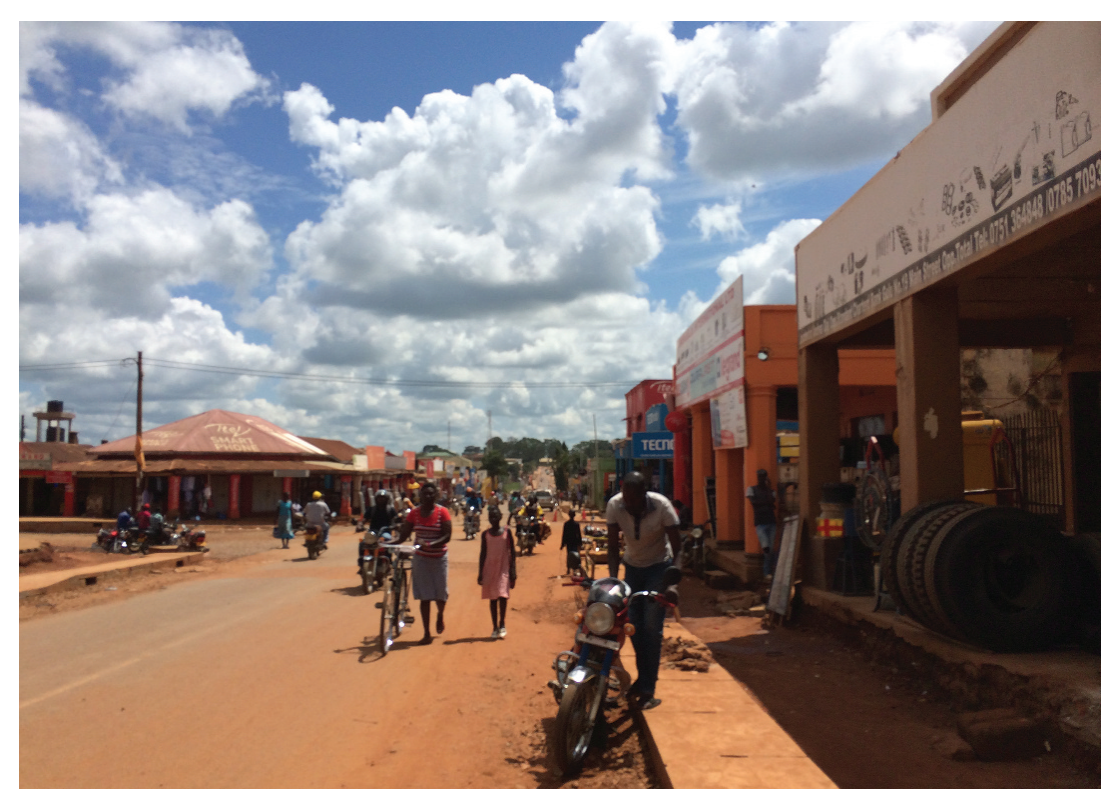

Figure 3. Gulu's main street, the Kampala- Gulu Highway looking north. Image by the authors.

an almost exclusively humanitarian economy (Branch 2011, 4). As a result, Gulu was referred to as the 'aid capital' of Northern Uganda (Büscher, Komujuni, and Ashaba 2018, 348).

After the Juba peace talks of 2006-2008, Northern Uganda was internationally recognized as a post-conflict region (Büscher, Komujuni, and Ashaba 2018, 349). Today, the slums that bloomed during that period of armed conflict have continued to expand, and social conditions have deteriorated. The population is generally young and very poor. Gulu is also facing growing disparities of wealth. The city's rising crime rates may be a harbinger of increased population insecurity (Branch 2011, 1). Inequality in Gulu has been compounded by land grabbing and the 'cadastral corruption' of elites (Büscher, Komujuni, and Ashaba 2018, 358). Moreover, accelerated urbanization is occurring haphazardly with virtually no planning controls to regulate the process (Mukwaya et al. 2018, 92), despite the substantial planning work that has been undertaken by Non-Government Organizations (NGOs) over many years (McBurney 2009, 3). Consequently, public space becomes more threatened by human occupation as informal squatter settlements proliferate on marginal areas such as wetlands and forest reserves (Mukwaya et al. 2018, 92).

\section{A new plan for Gulu}

In 2011, Gulu was nominated by the Ugandan National Development Plan as one of the four 'regional cities' to be developed as part of the planned growth of Uganda's urban infrastructure. To be awarded 'city status', the existing municipality needed to fulfil numerous conditions regarding infrastructure and population (Büscher, Komujuni, and Ashaba 2018, 356). Indeed, Gulu's population is projected to increase from just over 150,000 in 2018 to almost double that, 300,000 by mid-century (Mukwaya et al. 2018, 93). In 2019, the Ugandan government officially conferred city status on Gulu. 
This city status built on a substantial infrastructural/urbanization project launched by the World Bank in 2015. This project was framed as a move from humanitarian to development interventions and offered an alternative kind of engagement by aid agencies within urban areas (Büscher, Komujuni, and Ashaba 2018, 350). In 2015, the World Bank issued a report titled 'the growth challenge: can Ugandan cities get to work', in which it articulates a plea for better 'managing' urbanization to underpin Uganda's growth. Following its neo-liberal narrative on urban development, policymakers 'should invest in improving urban planning and coordination to deliver better services, jobs and opportunities, making cities more competitive' (Büscher, Komujuni, and Ashaba 2018, 357). ${ }^{3}$

In part due to its neo-liberal ethos, critiques are emerging from Gulu residents that the government and developers 'want to exploit poor people and bring in that which you might see in the USA or London' (In Valente 2017). Other residents living in informal, traditional housing feel the government stigmatizes houses made of mudbrick and grass thatching. They claim the government hides them from visitors and tourists, so the city looks 'urban and developed' for 'aid organizations, urbanization groups, or other wealthy groups who live in permanent [brick and mortar] houses' (Valente 2017).

\section{The development of suitability analysis}

Given the rapid growth of Gulu and divergent opinions about where and what form urban development should take, there is an opportunity for a comprehensive suitability analysis to be undertaken, which systematically considers what sites are most appropriate for development - from the multiple perspectives of the local community, the environment, existing transport infrastructure and land uses.

An early example of the regional assessment of suitability for urban development occurred in the 1920s when Lewis Mumford ventured that planning should encompass a holistic sense of a bioregion so that population 'will be distributed to utilize, rather than nullify or destroy, its natural advantages' (In Weller 2009, 167).

Decades later, lan McHarg developed his ecological planning method, which overlaid factors that constrain urban development (McHarg 1992, 57). McHarg's approach simply proposed that development should respond to the operation of natural processes (McHarg 1992, 81). As McHarg implored, 'let us ask the land where are the best sites' (McHarg 1992, 197). Such physiographic determinism suggests that natural processes should be a template for urban development (McHarg 1992, 81).

McHarg's method remains capable of determining where urban development should not occur on a large-scale regarding landscape conditions. However, it is not so useful in telling planners where development should occur (Weller 2009, 171). Current MultiCriteria Evaluation approaches that integrate with Geographic Information Systems respond to this weakness. Multi-Criteria Evaluation Geographic Information Systems is a process that combines and transforms evaluation data (input) into a resultant decision (output). The Multi-Criteria Evaluation procedures define a relationship between input and output maps and suggest optimum urbanization areas in relation to spatial criteria (Zhang et al. 2013, 742). 
Suitability analyses have increasingly become integral components of urban, regional and environmental planning (Zhang et al. 2013, 741). There is also a plethora of academic literature concerning suitability analyses that relate to different geographic contexts. These include China (Zhang et al. 2013, 741; Liu, Ke Zhang, and Borthwick 2014; Wang et al. 2017), India (Kumar and Shaikh 2013, 418), Australia (Pettit et al. 2015, 94; Chen 2016; Weller 2009), Iran (Lotfi, Habibi, and Koohsari 2009, 91), and Spain (Criado et al. 2017, 3), however there exist limited examples of suitability analysis in African countries generally, or Uganda in particular.

\section{The role of Co-Design}

Co-Design is a collaborative activity that uses an intentional design process to achieve a range of objectives (Blomkamp 2018). It is particularly useful at foregrounding contextual values and priorities as participants can translate and communicate local knowledge. If deployed during project development phases, it provides a potentially powerful method by which conventional top-down analyses and processes can be augmented with empirical knowledge (Steen, Manschot, and De Koning 2011; Burkett 2012; De la Pena 2017). It gives those with lived experience the opportunity to be involved in decision making within a project and to emphasize culturally specific values. Thus Co-Design avoids perpetuating the problems created by importing and applying 'foreign' models without sufficient understanding of the contextual values, which would impact their suitability and success.

Co-Design for planning sits within an established framework of communicative planning that emphasizes the role of different stakeholders or actors - the producers, the regulators, and the users (Madanipour 2006) - as contributors to the organization of the built environment (Hall 2014). It demands participation and involvement and the creation of processes and tools, which are essential components of the planning project.

\section{A contextualized suitability analysis for Gulu}

Given Gulu's rapid population growth and urbanization, and the availability of suitability analysis and Co-Design methods, the research question guiding this paper is:

What does a comprehensive suitability analysis informed by localized Co-Design activities determine is the most appropriate urban model for planners to accommodate Gulu's surging population growth?

This paper refers to four generic models for accommodating urban growth posited by renowned urban ecologist Richard Forman as a reference point in both the Co-Design activities and suitability analysis. The first is 'concentric zones' which involves compact growth around an existing city (Forman 2010, 202). The second is 'satellite cities', which involves urbanization in nodes distributed around a central city (Forman 2010, 201). The third is 'transportation corridors' and involves development along major radial transportation routes (Forman 2010, 201). The fourth is 'dispersed sites', which involves relatively low-density development, or sprawl, around the city (Forman 2010, 202) (Figure 4). Forman identified these models from a comprehensive morphological analysis of 38 urban regions from 32 nations, including several African examples (Forman 2010). 

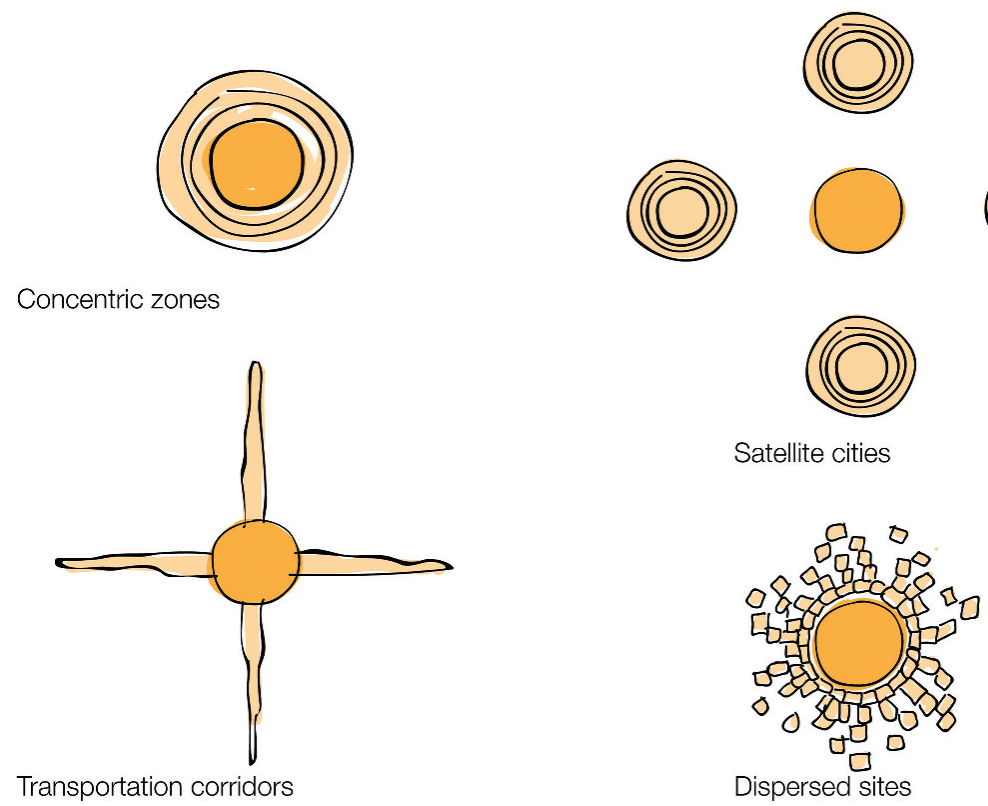

Figure 4. Richard T Forman has developed four typical spatial models for accommodating urban growth pictured. Figure traced by the authors from Forman (2010).

\section{Methods}

A suitability analysis was conducted using the ArcMap 10.5 'overlay analysis' tool (Esri 2020 b) to answer the research question. Users typically apply this tool in optimal site selection as a technique for applying a standard scale of values to diverse inputs to generate an 'integrated analysis' (Esri 2020b). The suitability analysis is underpinned by suitability factors which were determined through Co-Design focus group exercises.

\section{Co-Design to inform suitability factors}

To mediate the different perspectives and expectations of the research team and the project participants (Bull, Darko, and Parin 2007), and to identify and understand the local relevance of the potential suitability factors, a focus group exercise utilizing Co-Design was conducted with participants consisting of Ugandan senior planning officers, academics, politicians and council staff. There was variation in the sample group regarding age, gender and social background. However, as the research team consciously recruited a purposive, not a representative sample, respondents' sociodemographic background was not of critical significance. Specific knowledge of Gulu, based primarily on long-term residence, was of much greater importance (Carrington and Marshall 2008, 121).

The focus group exercises employed two Co-Design activities using custom-designed physical, interactive models. Two separate workshops were held over two days, and each involved over 15 participants, men and women. The models simulated urbanization in a dynamic, interactive, open-ended workshop. The use of interactive physical models is a Co-Design method that involves multiple stakeholders, often including individuals with no formal planning and design training in a parallel design process. Following the CoDesign activity, individuals or groups present their findings back in the process of collective reflection. This reflection and the discussion is recorded and analysed to 
interpret key themes which have emerged. These can then inform contextually appropriate factors for further interrogation, such as in the suitability analysis. The process is designed to be highly inclusive, equitable and appealing (Duckworth-Smith and Oliver 2019), encouraging participants to share tacit and experiential knowledge, learn from one another (Gordon and Baldwin-Philippi 2014), and build trust (Laurian 2009).

The Co-Design activity's interactive dynamics were framed around groups exploring one of Forman's growth models $(2010,202)$. The activity utilized a custom-designed interactive model that consisted of a 1:20,000 scaled base drawing of Gulu and the surrounding region (ten kilometres by ten kilometres) and various physical pieces that participants could place on the base map to represent either Urban Planning Areas, Landmark Functions or Movement Networks. The activity was undertaken in groups of three to six persons facilitated by urban design professionals and progressed through a series of prompts encouraging participants to consider priority areas for urban development based around one of the standard growth patterns. Facilitators would then respond to the discussion and encourage participants to place their own as a record of the exploratory discussion.

The Co-Design activity was run two times with three different groups over two days, and six group models were constructed. The activity ran for 60-90 minutes with each group, then providing feedback that was recorded. Participants were generally very engaged with the game process, as shown in the photos (Figure 5). The activity design allowed the

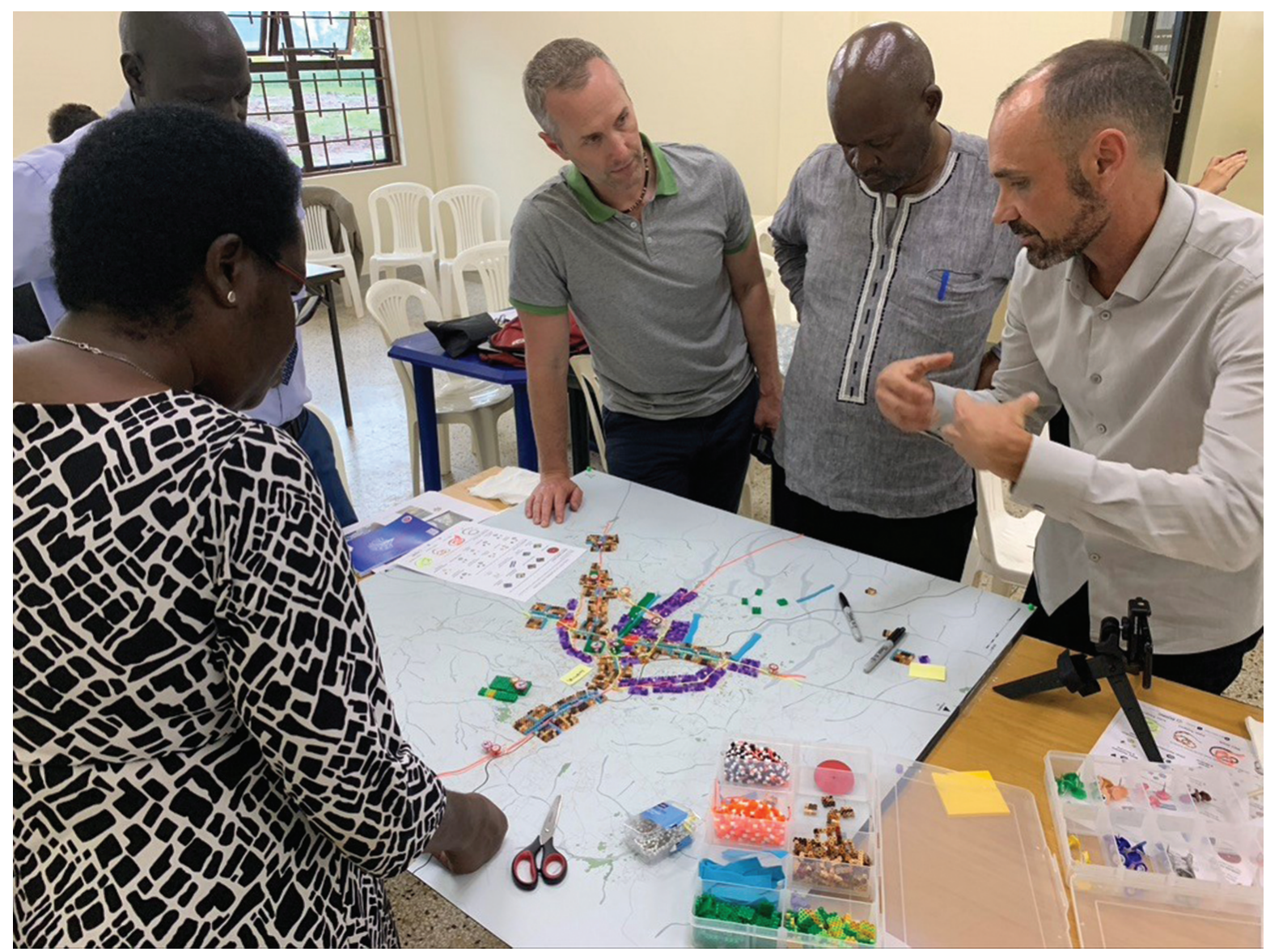

Figure 5. Gulu Co-Design. The activity utilized 1:20,000 scaled base drawings of Gulu and various physical pieces that participants could place on the base map. Image by the authors. 
recording of factors that participants felt should constrain urbanization (such as wetlands) or encourage urbanization (such as secondary road corridors). No attempt was made to derive 'quantitative outcomes' from the focus group exercises. Rather, they were used to understand the unique 'meanings, perceptions and interpretations of participants' concerning future urbanization patterns (Carrington and Marshall 2008, 120). Below, the focus group's key suitability factors are set out in the sub-models of the suitability analysis.

\section{The suitability analysis sub-models}

Given this suitability analysis's potential complexity, it has been broken down into three sub-models for clarity (Esri 2020b). These sub-models are 1) environment, 2) transportation and 3) land use. These parameters were chosen because they reflect dominant themes from the focus group exercise and because they are typical of many suitability analyses (Kumar and Shaikh 2013, Myagmartseren, Buyandelger, and Brandt 2017; Lotf, Habibi, and Koohsari 2009). Under each sub-model, a set of factors that present either constraints or opportunities for urbanization are identified.

\section{The environment sub-model}

Although many natural factors influence human settlements, the most fundamental are terrain, hydrological conditions, and land cover, which 'play leading roles' in the natural suitability evaluation (Wang et al. 2017, 2). Indeed, suitability analyses typically incorporate topographic factors such as elevation (Park et al. 2011, 106; Liu, Ke Zhang, and Borthwick 2014, 171; Wang et al. 2017, 4; McHarg 1992), slope (Park et al. 2011, 420; Myagmartseren, Buyandelger, and Anders Brandt 2017, 5; Criado et al. 2017, 5; Lotfi, Habibi, and Koohsari 2009; Kumar and Shaikh 2013; Al-Shalabi et al. 2006) and aspect (Al-Shalabi et al. 2006). Hydrological factors generally include surface water, e.g., rivers and lakes (Myagmartseren, Buyandelger, and Anders Brandt 2017, 90; Lotfi, Habibi, and Koohsari 2009; McHarg 1992), adjacent flood-prone land (Criado et al. 2017, 5; Al-Shalabi et al. 2006), groundwater recharge and water catchment areas (Liu, Ke Zhang, and Borthwick 2014, 172). They also include environmental factors such as areas of ecological value (Criado et al. 2017, 172; Liu, Ke Zhang, and Borthwick 2014) and vegetation cover (Wang et al. 2017, 2; Myagmartseren, Buyandelger, and Anders Brandt 2017, 5).

The focus group participants felt that future urban development should avoid Gulu's wetlands system and that such 'ecological determinants' should shape future urbanization patterns at a broad scale (Figure 6).

One example attendees cited was the Pece Channel immediately north of the Gulu town centre. As they said, it will be 'very costly to create a new one, so we will maintain it' to improve water quality and mitigate floods. There was a general feeling amongst participants that within future 'residential and mixed urban areas provision of public open space, green space is important' and that the wetlands system was a logical structure to inform this green-space provision. Finally, participants regarded that Gulu's extensive network of pedestrian paths, many of which run along green systems, should be maintained through the development process. 




Figure 6. Gulu wetlands system framed by low density, informal housing and agricultural plots. Image courtesy of Google Earth.

Under the environment sub-model, factors have been selected that should constrain urbanization, including wetland systems, forested areas, and slope. Data was sourced from Open Street Map (2019) and Shuttle Radar Topography Mission 30-metre Digital Elevation Model data from the Regional Centre For Mapping Resource For Development (2018).

\section{The transportation sub-model}

Suitability analyses typically incorporate transport infrastructure-related factors such as distance to rail networks (Wang et al. 2017, 2), major road networks (Wang et al. 2017, 171; Park et al. 2011; Kumar and Shaikh 2013; Liu, Ke Zhang, and Borthwick 2014, 171; Al-Shalabi et al. 2006) and existing urban centres (Wang et al. 2017, 2; Park et al. 2011; Myagmartseren, Buyandelger, and Anders Brandt 2017, 5; Lotfi, Habibi, and Koohsari 2009, 90).

Focus group participants felt that primary road infrastructure, such as Gulu Highway, should not be a focus of urban development because road infrastructure is congested due to 'through traffic, local traffic, and the activity which is on either side' and as such, there is a need to delineate roads that accommodate 'cargo traffic'. Similarly, attendees also felt that existing rail corridors should also be maintained to enable 'regional connectivity to Kampala (and elsewhere) in the future, should this currently cancelled rail service be reinstated. Other attendees felt that new satellite settlements could occur - separate to Gulu's existing urban footprint - at intersections of major roads to divert traffic from Gulu's core area. 
With primary roads protected from urban encroachment, attendees regarded that consolidated development could occur along secondary roads in the form of "higher density residential' development with 'ground floor commercial'. Such roads could also accommodate Gulu's bus network to deliver a 'higher-density urban footprint that complements public transport'.

Under the transportation sub-model, based on the elicitation of values from the focus group participants, existing major transport infrastructures were identified that present opportunities, or constraints, for urbanization. These include primary roads that present constraints to urban development, and secondary and tertiary roads that present opportunities for urban consolidation and transit connectivity.

\section{The land use sub-model}

Suitability analyses typically incorporate land-use factors, e.g., distance to educational and medical facilities (Wang et al. 2017, 5) or industrial areas (Al-Shalabi et al. 2006, 8). Focus group participants felt that Gulu's central area should not accommodate substantial further development because of existing 'congestion, overcrowding and pollution' and 'land parcels of inadequate size'. Moreover, attendees raised concerns about Gulu's food security and the need for 'preservation of land for food production', something they believed inappropriate development would 'squeeze'. Also, participants expressed concerns that existing public open spaces need to be maintained and new open spaces developed. ${ }^{4}$

Attendees instead proposed that education should be a driver of future urban development. They regarded that Gulu University should attract complementary facilities such as football pitches, colleges, and a health centre. Again, many contributors noted the potential of 'secondary satellite towns or regional hubs', which they felt could be based around resettlement camps and informal settlements. Participants asked, 'what is the future of these settlements? These are not formally accounted for or planned for; are these going to become centres in their own right?' In particular, they felt that 'affordable housing strategies should not displace the current population'. While generally supportive of satellite centre development, many focus group attendees were concerned not to propagate urban sprawl.

Under the land use sub-model, Gulu's existing major land uses that present opportunities and urbanization constraints are identified. Land uses that present opportunities include existing universities, schools and villages, all of which can be nodes around which urbanization can occur. Moreover, land uses that should curtail urbanization included existing agriculture and a wastewater plant which requires a substantial buffer zone. Finally, areas a substantial distance from existing urban areas requiring considerable transportation investments were considered constrained.

\section{Weighting the suitability factors}

There is a relative consensus in the literature that weighting of the suitability factors presents a 'difficult problem' as it 'introduces subjectivity into the decision-making process since the weight is [often] assigned arbitrarily to each set of factors' (Chen $2016,50)$. As researchers explain, this can lead to considerable variations in results 
depending on the 'interests of the experts who are assigning the weights' (Flitter et al. $2013,22)$. As a result of such challenges, 'there remains still no widely accepted method for weight determination' (Zhang et al. 2013, 742).

Analytic Hierarchy Process was applied to tackle this problem, which is a 'theory of measurement through pairwise comparisons' to derive priority scales (Saaty 2008, 83). In constructing a set of pairwise comparison matrices, M-Macbeth software was used (Bana e Costa, De Corte, and Vansnick 2020) to compare all possible pairs of suitability analysis criteria (e.g., road access and rail access) and to weight the relative importance of one criterion over another (Saaty 2008, 85).

\section{Computing the results}

With the sub-models, factors and weightings in place, the factors maps were converted into a raster data environment, in Arcmap 10.5 at a resolution of 50 by 50 metres in Arclnfo Grid files. Since the input factors layers were in different numbering systems with different ranges, they were reclassified into a standard preference scale (Esri 2020a). The suitability score is out of nine, with a score of one denoting very low suitability, five medium suitability and nine very high suitability. The median score is five, and this divides the rankings between areas broadly suitable or unsuitable for urbanization. Finally, the weighted linear summation algorithm was applied, which multiplies all grid cells of a layer by their weight. The table below (Table 1) sets out the weightings derived from the pairwise comparison process for the sub-models and their respective factors.

Table 1. This table sets out the factor weightings (derived from the pairwise comparison process) classifications and associated suitability scores.

\begin{tabular}{|c|c|c|c|c|}
\hline Sub-model & Weighting & Suitability factors & Classifications & Preference score \\
\hline Environment sub-model & $x^{2}$ & $\begin{array}{l}\text { Constrain urbanization on steep slopes } \\
\text { (degrees) }\end{array}$ & $\begin{array}{l}\text { Forests } \\
\text { Orchard } \\
\text { Shrub } \\
\text { Not forest } \\
0-3.8 \\
3.8-7.7 \\
7.7-11.6 \\
11.6-15.5 \\
15.5-19.4 \\
19.4-23.3 \\
23.3-27.2 \\
27.2-31.1 \\
31.1-35.0 \\
0-25 \\
25-50 \\
50-75 \\
75-100 \\
100-125 \\
125-150 \\
150-175 \\
175-200 \\
>200\end{array}$ & $\begin{array}{l}1 \\
1 \\
3 \\
9 \\
9 \\
8 \\
7 \\
6 \\
5 \\
4 \\
3 \\
2 \\
1 \\
1 \\
2 \\
3 \\
4 \\
5 \\
6 \\
7 \\
8 \\
9\end{array}$ \\
\hline
\end{tabular}


Table 1. (Continued).

\begin{tabular}{|c|c|c|c|c|}
\hline Sub-model & Weighting & Suitability factors & Classifications & Preference score \\
\hline \multirow{13}{*}{$\begin{array}{l}\text { Transport infrastructure } \\
\text { sub-model }\end{array}$} & 0.17 & & & \\
\hline & 0.52 & Deliver urbanization along existing & $0-100$ & 9 \\
\hline & & secondary and tertiary roads & $100-200$ & 8 \\
\hline & & potentially well served by public & $200-300$ & 7 \\
\hline & & transport- bus & $300-400$ & 6 \\
\hline & & (metres from road centreline) & $400-500$ & 5 \\
\hline & & & $500-600$ & 4 \\
\hline & & & $600-700$ & 3 \\
\hline & & & $700-800$ & 2 \\
\hline & & & $>800$ & 1 \\
\hline & 0.48 & Avoid urbanization on existing primary & $<50 \mathrm{~m}$ & 1 \\
\hline & & roads which pose accident and & $50-100$ & 3 \\
\hline & & $\begin{array}{l}\text { pollution risks (metres from road } \\
\text { centreline) }\end{array}$ & $>100$ & 9 \\
\hline \multirow[t]{48}{*}{ Land use sub-model } & 0.33 & & & \\
\hline & 0.14 & Deliver urbanization around schools & $0-100$ & 9 \\
\hline & & (metres from school) & $100-200$ & 8 \\
\hline & & & $200-300$ & 7 \\
\hline & & & $300-400$ & 6 \\
\hline & & & $400-500$ & 5 \\
\hline & & & $500-600$ & 4 \\
\hline & & & $600-700$ & 3 \\
\hline & & & $700-800$ & 2 \\
\hline & & & $>800$ & 1 \\
\hline & 0.01 & Constraining urbanization in areas of & Agriculture & 1 \\
\hline & & existing agriculture & Not agriculture & 9 \\
\hline & 0.22 & Focus urbanization around existing & $0-200$ & 9 \\
\hline & & villages (metres from the existing & $200-400$ & 8 \\
\hline & & village) & $400-600$ & 7 \\
\hline & & & $600-800$ & 6 \\
\hline & & & $800-1000$ & 5 \\
\hline & & & $1000-1200$ & 4 \\
\hline & & & $1200-1400$ & 3 \\
\hline & & & $1400-1600$ & 2 \\
\hline & & & $>1600$ & 1 \\
\hline & 0.36 & Avoid urbanization in areas & $0-2000$ & 9 \\
\hline & & a substantial distance from existing & $2000-4000$ & 8 \\
\hline & & urban areas (metres from Gulu from & $4000-6000$ & 7 \\
\hline & & town centre) & $6000-8000$ & 6 \\
\hline & & & $8000-10,000$ & 5 \\
\hline & & & $10,000-12,000$ & 4 \\
\hline & & & $12,000-14,000$ & 3 \\
\hline & & & $14,000-16,000$ & 2 \\
\hline & & & $>16,000$ & 1 \\
\hline & 0.17 & Avoid urbanization in areas adjacent to & $0-100$ & 1 \\
\hline & & the wastewater plant & $100-200$ & 2 \\
\hline & & & $200-300$ & 3 \\
\hline & & & $300-400$ & 4 \\
\hline & & & $400-500$ & 5 \\
\hline & & & $500-600$ & 6 \\
\hline & & & $600-700$ & 7 \\
\hline & & & $700-800$ & 8 \\
\hline & & & $>800$ & 9 \\
\hline & 0.1 & Focus urbanization around Gulu & $0-200$ & 9 \\
\hline & & University & $200-400$ & 8 \\
\hline & & & $400-600$ & 7 \\
\hline & & & $600-800$ & 6 \\
\hline & & & $800-1000$ & 5 \\
\hline & & & $1000-1200$ & 4 \\
\hline & & & $1200-1400$ & 3 \\
\hline & & & $1400-1600$ & 2 \\
\hline & & & $>1600$ & 1 \\
\hline
\end{tabular}




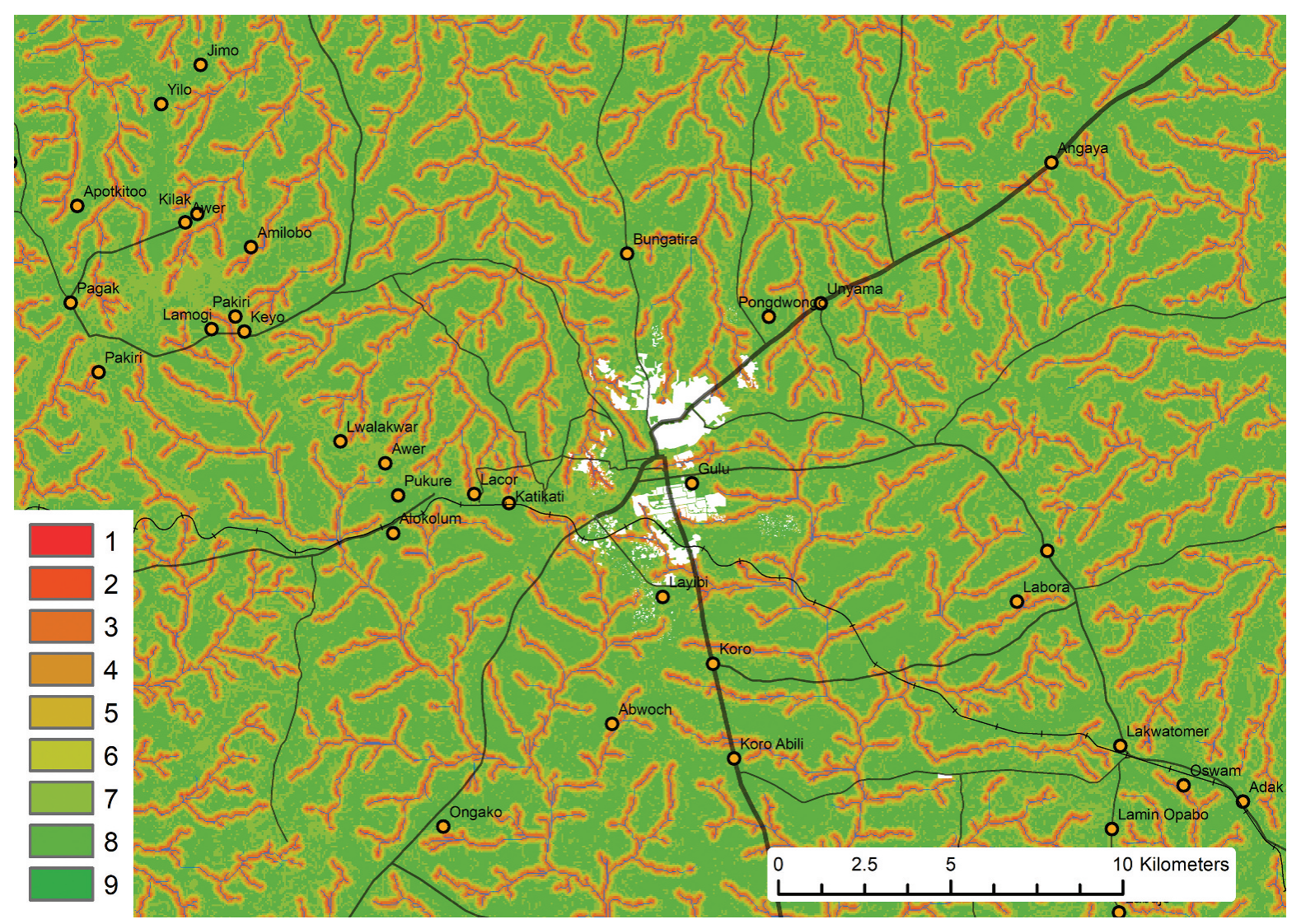

Figure 7. The environment sub-model map shows the relative suitability for urbanization ( 1 is least suitable, 9 most suitable). This map illustrates the dominance of constraints such as Gulu's extensive network of wetlands and, to a lesser degree, areas of steep slopes that reduce the feasibility of urban development. Figure by the authors.

\section{Results}

Discussed below are the results of the four sub-models that combine to form an overall suitability map. The environment sub-model map (Figure 7) illustrates the dominance of constraints such as Gulu's extensive network of wetlands and, to a lesser degree, areas of steep slopes that reduce the feasibility of urban development. While developers could override such constraints, this will incur a high cost in flood mitigation and adaption, which reduces development feasibility - and ultimately amenity, liveability, and resilience.

The transportation sub-model map (Figure 8) shows that areas adjacent to existing secondary and tertiary roads are the best served by existing infrastructure and future public transport. In keeping with focus group responses, the primary roads are regarded as unsuitable for urbanization so that they are maintained as efficient vehicular routes.

The land use sub-model map (Figure 9) reveals the availability of education assets likes schools and Gulu University. It also reveals opportunities presented by peri-urban villages around which urbanization can coalesce into urban centres built on existing patterns yet alleviate some of the growth pressures on Gulu's core area. 


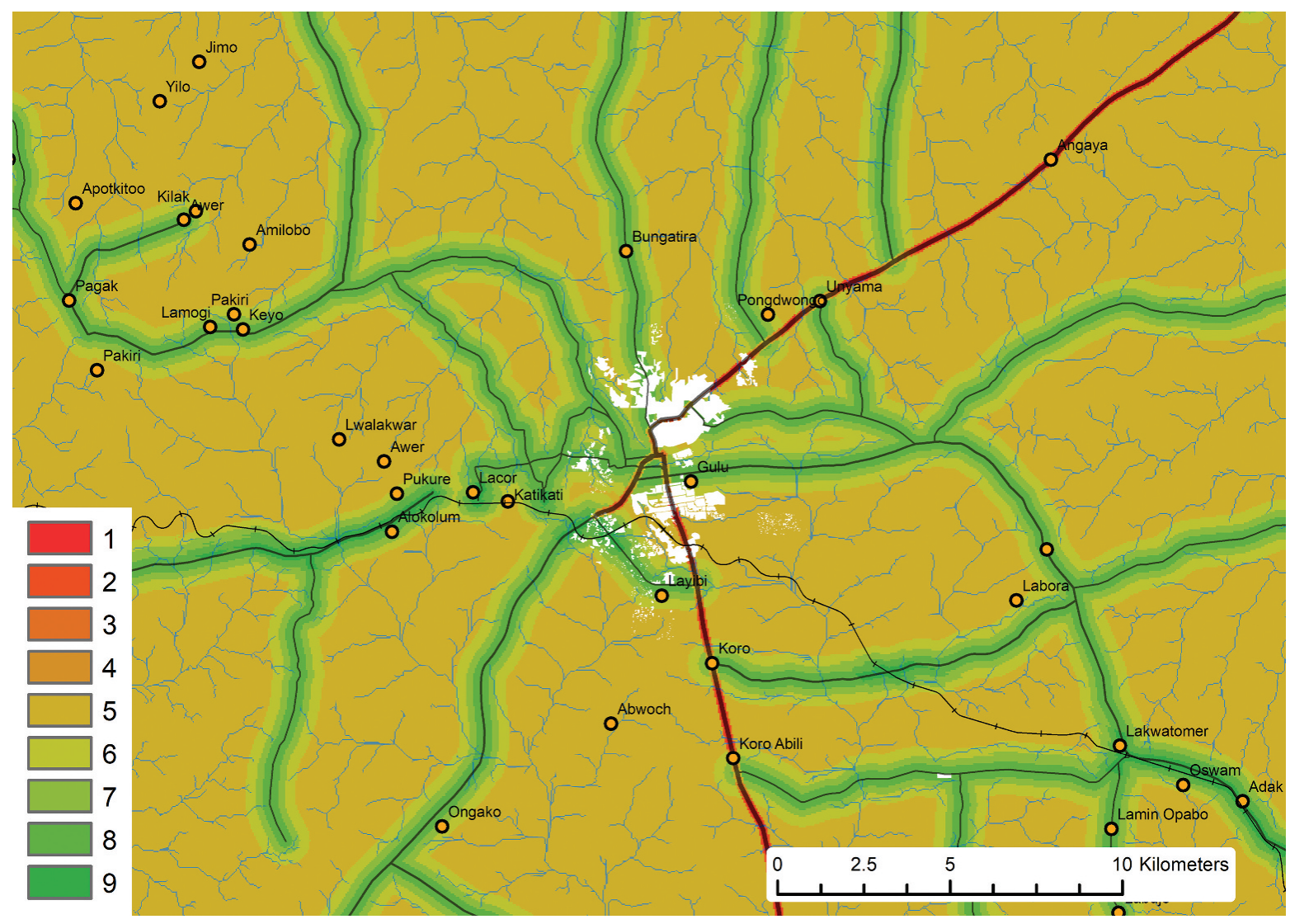

Figure 8. The transportation sub-model map shows the relative suitability for urbanization (1 is least suitable, 9 most suitable). The map reveals that areas adjacent to existing secondary and tertiary roads are the best served by existing infrastructure and public transport. Figure by the authors.

The overall suitability analysis map was generated from a weighted combination of the environment, transportation, and land use sub-model maps. This map reveals areas suitable for urbanization (with a preference score of 7 or 8 ) in the immediate surrounds of Gulu's existing urban footprint, then extending along secondary and tertiary road networks and coalescing around existing village structures (Figure 10). This suitability analysis indicates that, in broad terms, corridor development on suitable roads, combined with limited satellite centre and concentric zone development, is the most appropriate pattern of urban development for Gulu.

\section{Discussion}

This paper has documented a suitability analysis informed by a customized locally involved Co-Design process to ground test generic models of urbanization in Gulu against local environmental, transportation and land use factors (Forman 2010, 202). The hybrid methodology of Co-Design and suitability analysis was targeted at contextualizing generic urban models' performance to understand better how local culture and its attendant values and ambitions could be integrated into an urban planning process. This exercise had some limitations. The employment of additional factors in the 


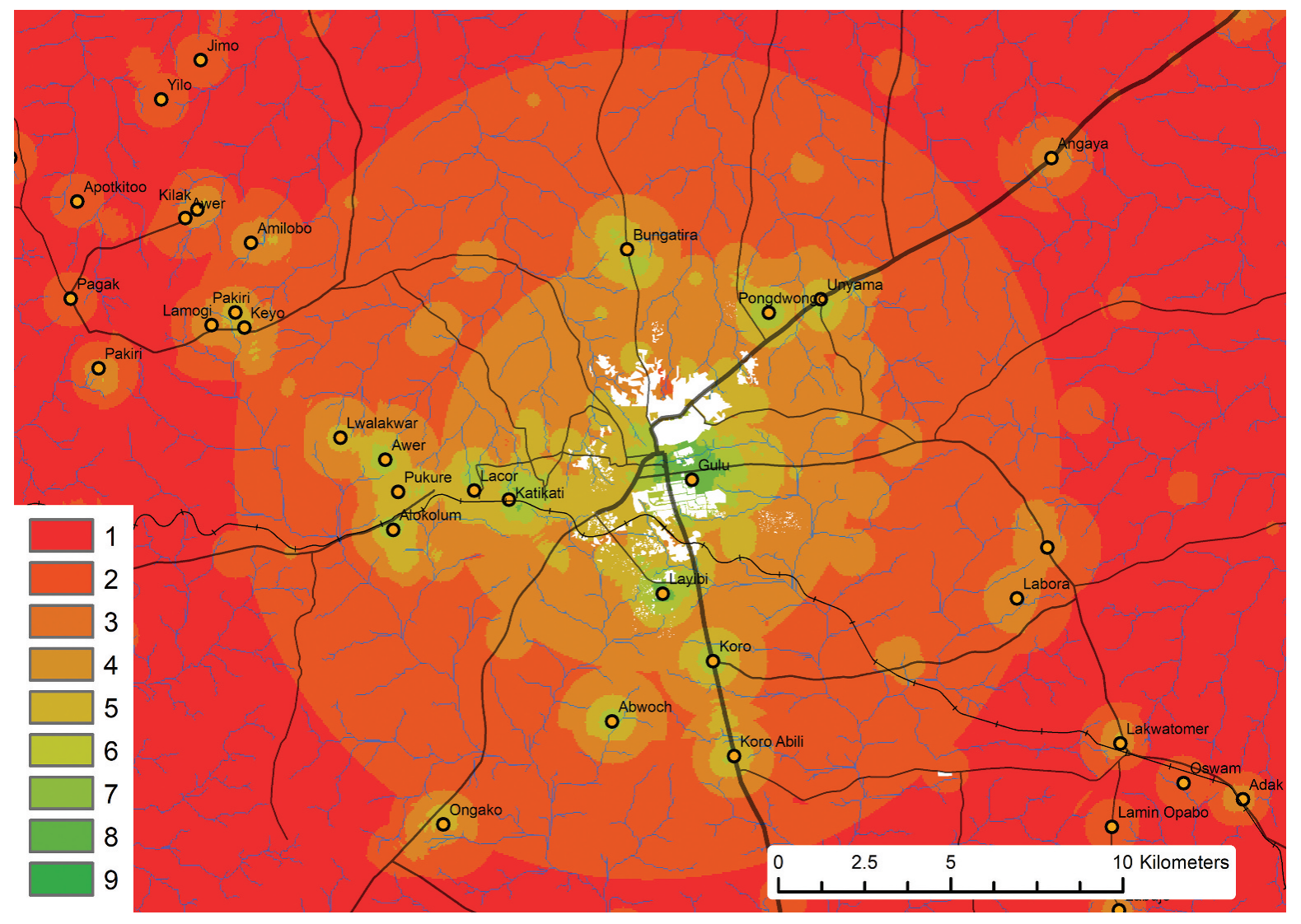

Figure 9. The land use sub-model map shows the relative suitability for urbanization ( 1 is least suitable, 9 most suitable). It reveals opportunities presented by education assets likes schools and Gulu University, and peri-urban villages, around which urbanization can coalesce into urban centres. Figure by the authors.

suitability analysis was constrained by a relative lack of geospatial data for Uganda and Gulu. Also, it is conceded that different suitability analysis factors and weightings could change the results.

\section{The benefits of the corridor model in Gulu}

As stated, the contextual suitability analysis indicates that, in broad terms, corridor development on suitable roads, in combination with limited satellite centre and concentric zone development, is the most appropriate pattern of urbanization for Gulu (Figures 11 and 12).

Firstly, this form of corridor development on elevated land preserves Gulu's extensive wetland systems, which deliver flood mitigation and water quality benefits, as well as substantial reserves of public open space. The latter being important given Gulu's current under-provision of public open space (Mukwaya et al. 2018, IV).

Secondly, the model preserves land for agriculture, running adjacent to the wetland systems. Embedding urban agriculture is key as it plays a critically important role in Gulu's post-conflict economy (Büscher, Komujuni, and Ashaba 2018) (Figure 13). As Adam Branch explains, urbanisms that respond to this 'heterogeneity of the urban, while also recognizing the continued centrality of the rural, require practical experimentation' (Branch 2011, 


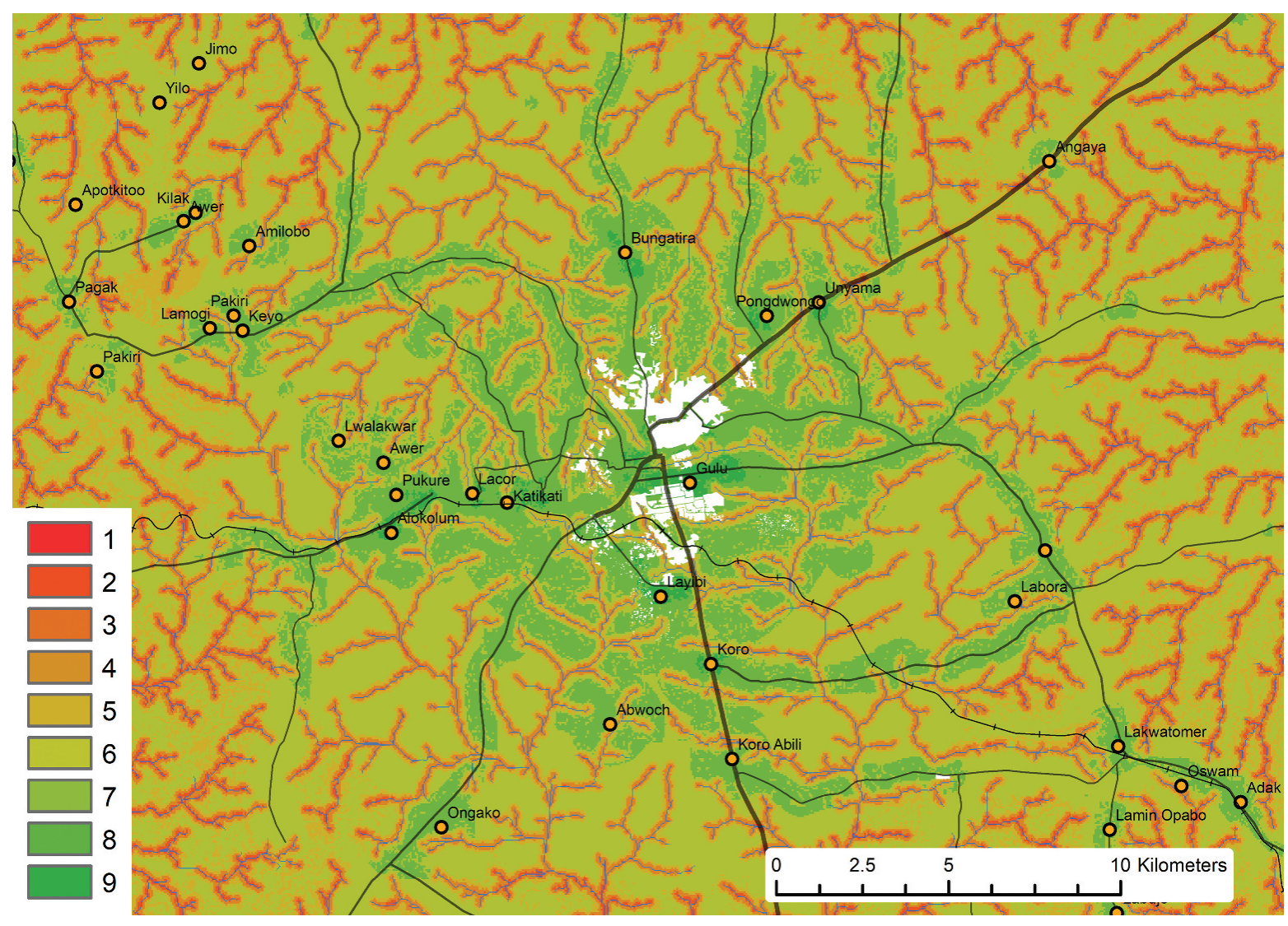

Figure 10. The overall suitability analysis map shows the relative suitability for urbanization (1 is least suitable, 9 most suitable). This map reveals areas suitable for urbanization in the immediate surrounds of Gulu's existing urban footprint, then extending with secondary and tertiary road networks and coalescing around existing peri-urban villages. Figure by the authors.

18). In Gulu, the corridor urban model could enable this synergy between the urban and the rural, which balances local economic and productive self-sufficiency, landscape character, biodiversity, and urban development aspirations.

Thirdly, the preservation of pedestrian paths and the wetland system will ideally mean that walking, as a primary means of transport, will be further encouraged. In turn, this might help avoid generating car dependency and related inequities and provide a possible scaffold for active transport and affordable micro-mobility options into the future (McBurney 2009, 8).

Fourthly, the concentration of urban development along appropriate secondary and tertiary corridors will deliver high levels of public transport accessibility through local bus systems and support the important 'informal' public transport economy. Moreover, residential and commercial activities will spread out from these corridor buildings into roadside stalls (Knebel 2012,4). These local corridors will support commercial activity along the main routes of travel and at key intersections (McBurney 2009, 14). Providing such opportunities is important in Gulu - because the micro commercial enterprise is crucial in avoiding urban poverty (McBurney 2009, 21) (Figure 14). As such, it should be sustained and encouraged in urban development proposals (McBurney 2009, 8). Moreover, limiting urban development along 


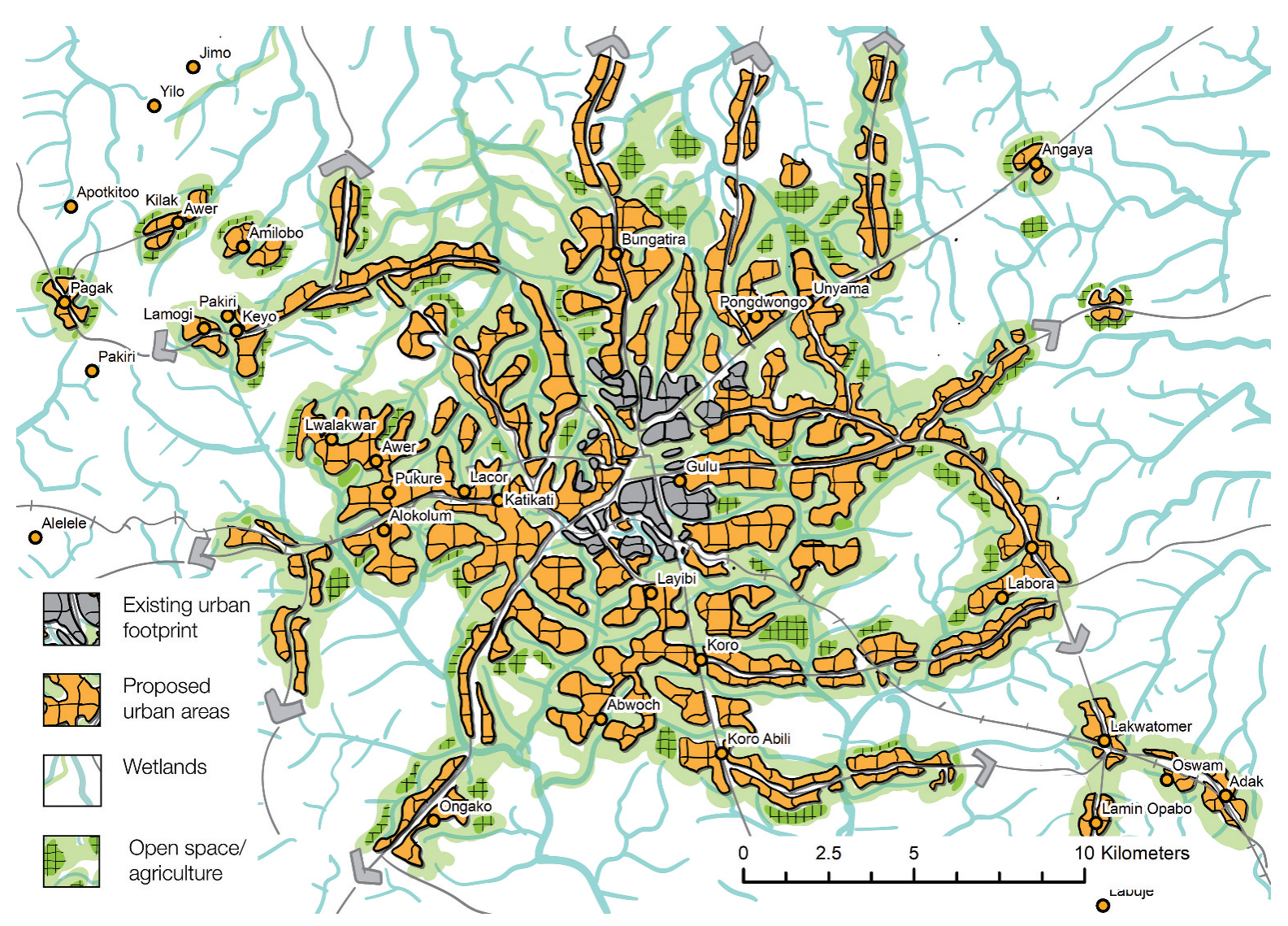

Figure 11. This figure interprets the suitability analysis findings into a spatial diagram. Note, this figure is indicative only. Figure by the authors.

primary roads will tackle very high levels of traffic congestion and fatalities that are common in Uganda (United Nations Habitat, and Ministry of Lands Housing and Urban Development 2016, 8).

Fifthly, the proposed model is sensitive to existing topography, forests and pathways, seeking to preserve as much as possible of existing thoroughfares and place-markers (McBurney 2009, 20). This retention is significant because decades of AIDS, armed conflict, and associated food insecurity have significantly disrupted pre-existing patterns of land ownership, combined with changes in the physical landforms and vegetation coverage that previously defined ownership boundaries (McBurney 2009, 20). In some parts of Gulu, these processes were significantly accelerated by international aid agencies' interventions both during the war and in the post-conflict period (McBurney 2009, 20). For some Acholi elders, Gulu had produced a 'lost generation of Acholi, addicted to money, disconnected from their roots in the land and without even basic cultural knowledge' (Branch 2011, 7).

Sixthly, by embedding some satellite centre development into a network of urban corridors with appropriate public transport, it will avoid peri-urban enclaves for the wealthy elite that are only accessible by private transport. This model is increasingly prevalent in many African countries and exacerbates 'socio-spatial segregation and fragmentation' (Van Noorloos and Kloosterboer 2017, 1).

Finally, by coalescing these urban centres around existing peri-urban villages, it will reinforce the 'natural' development of legible communities, and with appropriate planning, define limits to maintain a clear identity between neighbouring 'urban villages' (McBurney 2009, 15). 


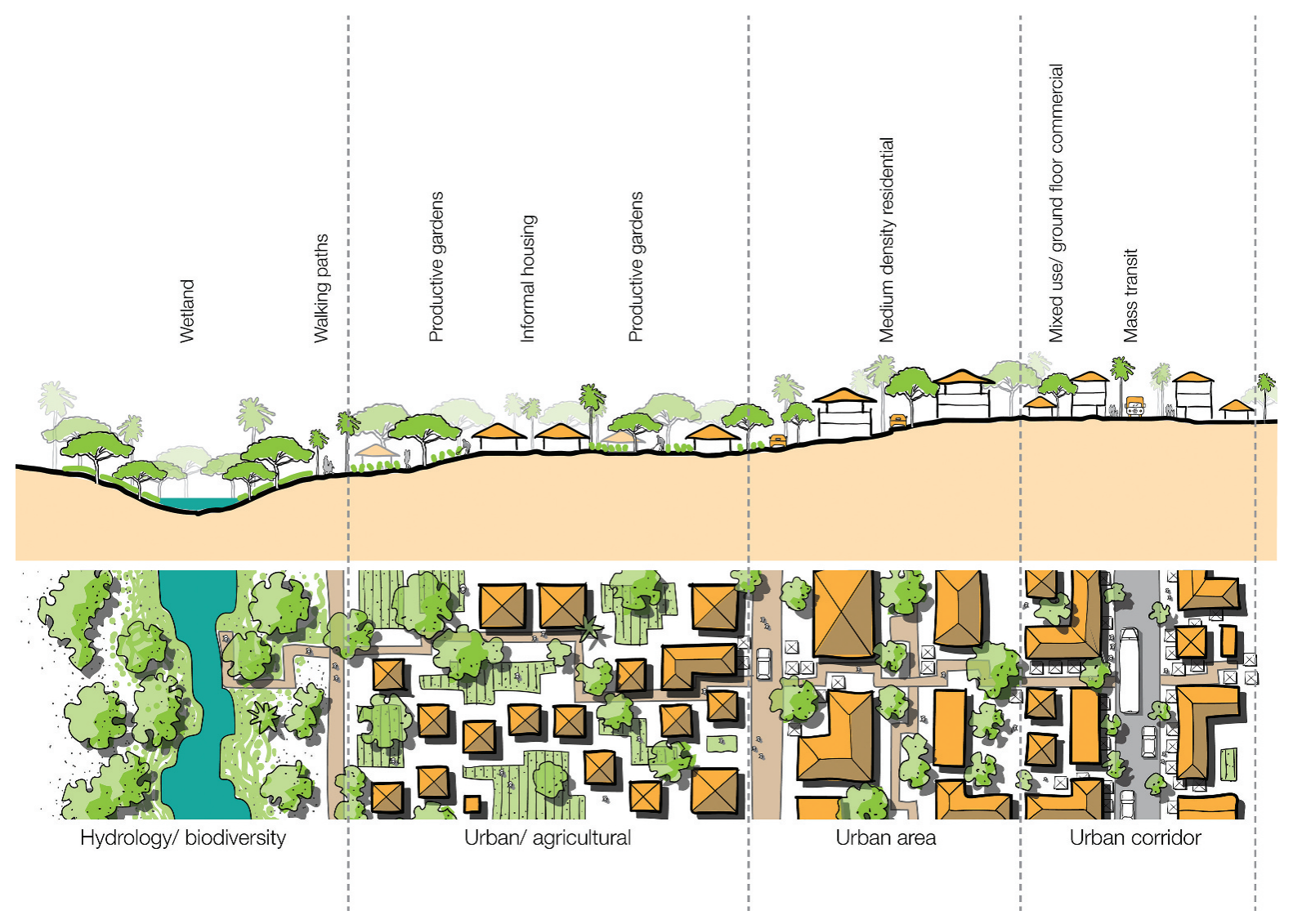

Figure 12. Corridor development on elevated land provides residents with easy access to public transport and economic opportunities and preserves Gulu's extensive wetland systems, which deliver flood mitigation and water quality benefits, as well as public open space. Figure adapted from the New Urbanist transect diagram. Note, this figure is indicative only. Figure by the authors.
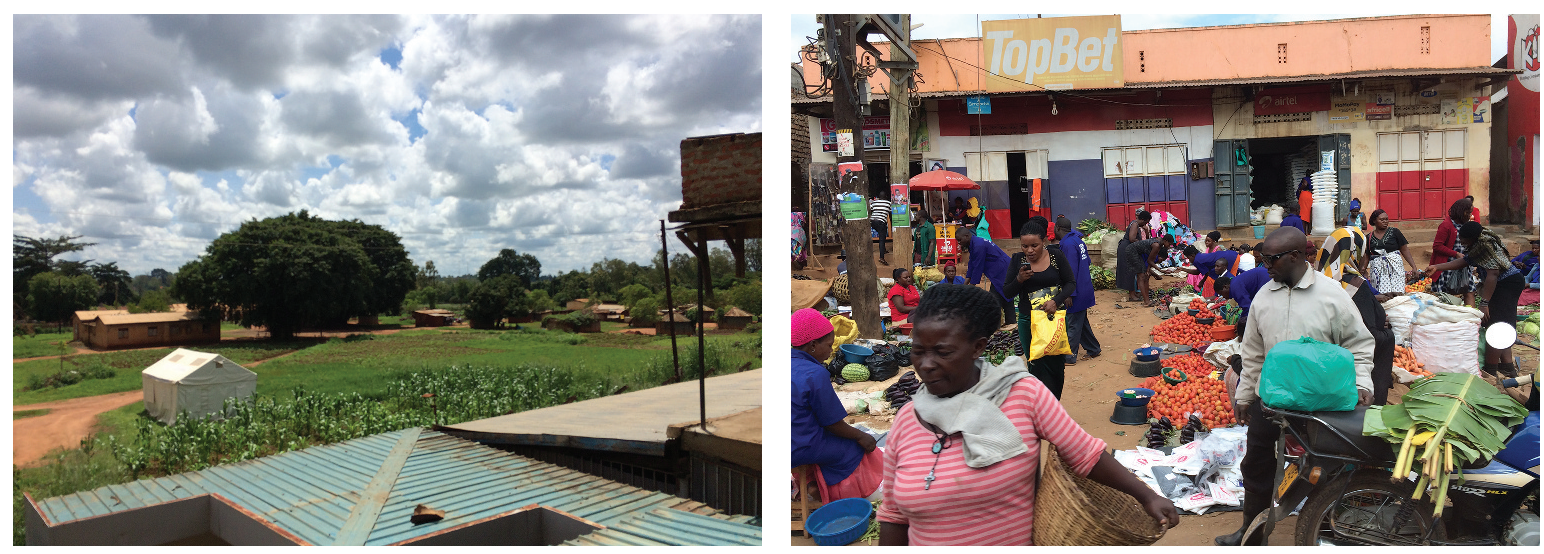

Figure 13. The preservation of land for agricul- Figure 14. Thriving micro commercial enterprise ture is of critical importance in that it is one (pictured) is crucial in the avoidance of urban povmeans of allowing residents to feed themselves. erty. Image by the authors. Image by the authors. 


\section{Further research}

From at least the mid-1990s onwards, there has been a growing recognition that considering Africa's rapid urban growth, greater attention needed to be given to 'the specificities of African urbanism' (Pieterse 2011, 6). However, during the late-1990s and into the 2000s, and reflecting the then-dominant developmental model of the 'antipoverty agenda', this need became somewhat neglected, as much research became focused on urban deprivation, specifically, and planning policy became characterized by what could be called a kind of 'crude managerialism' (Pieterse 2011, 152-153). In other words, the entire approach to Africa's new urbanism became dominated by 'simplistic extrapolations that we need to "manage" a so-called disastrous tendency' (Pieterse 2011, 5). Certainly, there have been some notable exceptions to this general trend. In particular, the work of various Africanist cultural geographers, and urban anthropologists, has provided valuable insights into the African experience of the new urbanism in locations across the continent (for an overview of some of this work see Pype, Van Wolputte, and Melice 2012; Pieterse 2011). However, these important contributions notwithstanding, it remains the case that further research needs to be done to understand better the precise challenges that Africa's new urbanism is generating and to develop responsive planning processes - through greater collaboration with urban residents themselves - to develop more compelling planning models for the future.

\section{Conclusion}

Like many other African cities, Gulu is experiencing rapid urbanization, which is generating a range of challenges concerning: institutional weaknesses, financial constraints, political interference, corruption, a mixing of urban management with politics, and leniency in enforcement (Mukwaya et al. 2018, VI), and a lack of secure land tenure (Mutuku, Boerboom, and Madureira 2019, 295), and doubtless many other factors besides. However, the most appropriate response to these is not to cast them as 'disastrous tendencies', which require a more managerialist response. On the contrary, as various experts have pointed out, in Gulu's case, specifically, many of these elements have been in practice made more complicated by the provisions of successive 'top-down' municipal development plans (Mukwaya et al. 2018, VI). Rather, a better way forward may be to develop more suitable city plans, ones that are more attentive to local people's needs, to the material realities of their physical environments, and which pay heed to their aspirations for them to own their future cities.

This paper has attempted to forward that agenda by exploring how planners can deploy a contextually relevant suitability analysis informed by a unique and inclusive Co-Design activity that elicits and translates insights from diverse participants to select an urban model reconciled with many of the challenges of urbanization. In Gulu's case, these challenges include maintaining agricultural productivity, providing public open space, public transport connectivity and enabling micro-economic activity. This research has revealed that for Gulu, the urban corridor model can potentially form a robust urban planning framework to engage with the kinds of challenges that the new city is facing and yield an urban form reconciled with Gulu's social, cultural and natural landscapes. 


\section{Notes}

1. While this section does generalize, to some degree, across the African continent, the great diversity of African countries is recognized (For example see Jacobs 2021).

2. Acholiland refers to the region traditionally inhabited by the Acholi people in Northern Uganda and South Sudan.

3. These ambitions are encapsulated in a 2019 'request for proposals' by Gulu Municipal Council for a 'local and global' consulting firms to develop 'sustainable urban development plans' for Gulu.

4. The Gulu municipality area is not well served with public open space. The current provision of public open space per 1,000 residents is only 0.91 hectares (Mukwaya et al. 2018, IV).

\section{Acknowledgments}

This article emerged from the workshop 'Urban Planning for the Future Gulu City' held at Gulu University on 4-5 June 2019. We want to thank Prof. G. L. Openjuru, Vice-Chancellor of GU, for so kindly hosting the event, Dr. Raphael Aregu for all his work in bringing it about, and all of the participants for taking part in the event. We gratefully acknowledge the UWA Research Collaboration Award 'Creating Smarter Cities in East Africa', which funded the project, and Prof. Benjamin Smith for all his support.

\section{Disclosure statement}

No potential conflict of interest was reported by the author(s).

\section{ORCID}

Julian Bolleter (D) http://orcid.org/0000-0002-1514-2007

Richard Vokes (D http://orcid.org/0000-0003-2862-7203

Anthony Duckworth (D) http://orcid.org/0000-0003-1966-7211

Paula Hooper (iD http://orcid.org/0000-0003-4459-2901

\section{References}

Al-Shalabi, M. A., S. B. Mansor, N. B. Ahmed, and R. Shiriff. 2006. "GIS Based Multicriteria Approaches to Housing Site Suitability Assessment." XXIII FIG Congress, Shaping the Change, Munich, Germany, October.

Bana e Costa, C., J.-M. De Corte, and J.-C. Vansnick. 2020. "M-Macbeth: A Multiple Criteria Decision Support System." M-Macbeth, April 28. www.m-macbeth.com

Blomkamp, E. 2018. "The Promise of Co-design for Public Policy." Australian Journal of Public Administration 77 (4): 729-743. doi:10.1111/1467-8500.12310.

Bolleter, J. 2019. Desert Paradises: Surveying the Landscapes of Dubai's Urban Model. London: Routledge.

Bolleter, J., and R. Cameron. 2021. "A Critical Landscape and Urban Design Analysis of Egypt's New Administrative Capital City." Journal of Landscape Architecture 16 (1): 8-19.

Branch, A. 2011. "From Camp to Slum: The Politics of Urban Displacement in Gulu Town, Uganda." Uganda. March 5.

Bull, C., R. Darko, and C. Parin. 2007. "Urban Design for a Cross Cultural Future." In Cross- Cultural Urban Design, edited by C. Bull, D. Boontharm, C. Parin, R. Darko and G. Tapie, 208-234. Abingdon, UK: Routledge.

Burkett, I. 2012. "An Introduction to Co-design." Saatavissa. http://design4socialinnovation.com.au/wp-content /uploads/2014/09/An-Introduction-to-Co-Design-by-Ingrid-Burkett.pdf [Accessed 21 September 2015] 
Büscher, K., S. Komujuni, and I. Ashaba. 2018. "Humanitarian Urbanism in a Post-conflict Aid Town: Aid Agencies and Urbanization in Gulu, Northern Uganda." Journal of Eastern African Studies 12 (2): 348-366. doi:10.1080/17531055.2018.1456034.

Carrington, K., and N. Marshall. 2008. "Building Multicultural Social Capital in Regional Australia." Rural Society 18 (2): 117-130. doi:10.5172/rsj.351.18.2.117.

Chen, S. 2016. "Land-use Suitability Analysis for Urban Development in Regional Victoria: A Case Study of Bendigo." Journal of Geography and Regional Planning 9 (4): 47. doi:10.5897/JGRP2015.0535.

Criado, M., A. Martínez-Graña, F. Santos-Francés, S. Veleda, and C. Zazo. 2017. "Multi-criteria Analyses of Urban Planning for City Expansion: A Case Study of Zamora, Spain." Sustainability 9 (10): 1850. doi:10.3390/su9101850.

De Boeck, F. 2011. "Inhabiting Ocular Ground: Kinshasa's Future in the Light of Congo's Spectral Urban Politics." Cultural Anthropology 26 (2): 263-286.

De la Pena, D. 2017. Design as Democracy: Techniques for Collective Creativity. Washington, DC: Island Press.

Duckworth-Smith, A., and G. Oliver. 2019. Australian Urban Design Research Centre Research P4: A Summary Report on the Research and Development of Innovative Tools for Community Engagement, Communication and Collaborative Design for Planning and Urban Design Policy. Perth: University of Western Australia.

Esri. 2020a. "How Weighted Overlay Works." Esri, February 22. https://desktop.arcgis.com/en/arc map/10.3/tools/spatial-analyst-toolbox/how-weighted-overlay-works.htm

Esri. 2020b. "Understanding Overlay Analysis." Esri, February 26. https://desktop.arcgis.com/en/ arcmap/latest/tools/spatial-analyst-toolbox/understanding-overlay-analysis.htm

Flitter, H., P. Laube, P. Luscher, S. Rogers, and S. Hagi. 2013. Suitability Analysis. Zurich: Geographic Information Technology Training Alliance.

Forman, R. 2010. Urban Regions: Ecology and Planning beyond the City. Cambridge: Cambridge University Press.

Goodfellow, T. 2010. "'The Bastard Child of Nobody'?: Anti-planning and the Institutional Crisis in Contemporary Kampala." Crisis States Research Centre Papers Series No. 2.

Gordon, E., and J. Baldwin-Philippi. 2014. "Playful Civic Learning: Enabling Lateral Trust and Reflection in Game-based Public Participation." International Journal of Communication 8: 28.

Hall, P. 2014. Cities of Tomorrow: An Intellectual History of Urban Planning and Design since 1880. 4th ed. Oxford: Blackwell.

Hickey, S. 2013. "Beyond the Poverty Agenda? Insights from the New Politics of Development in Uganda." World Development 43: 194-206. doi:10.1016/j.worlddev.2012.09.007.

Jacobs, S. 2021. "Africa Is a Country." January 23. https://africasacountry.com/

Knebel, N. 2012. "In Search of a Model for the African Metropolis: Observations and Contributions over Ten Years of Practice, Teaching and Research in Ethiopia." April 21. https://mygutech.gutech. edu.om/wordpress/wp-content/uploads/2016/10/KNEBEL-N_2012_African-Perspectives_In-

Search-of-a-Model-for-the-African-Metropolis.pdf

Kumar, M., and V. R. Shaikh. 2013. "Site Suitability Analysis for Urban Development Using GIS Based Multicriteria Evaluation Technique." Journal of the Indian Society of Remote Sensing 41 (2): 417-424. doi:10.1007/s12524-012-0221-8.

Laurian, L. 2009. "Trust in Planning: Theoretical and Practical Considerations for Participatory and Deliberative Planning." Planning Theory \& Practice 10 (3): 369-391. doi:10.1080/14649350903229810.

Liu, R., Z. Z. Ke Zhang, and A. G. L. Borthwick. 2014. "Land-use Suitability Analysis for Urban Development in Beijing." Journal of Environmental Management 145: 170-179. doi:10.1016/j.jenvman.2014.06.020.

Lotfi, S., K. Habibi, and M. J. Koohsari. 2009. "An Analysis of Urban Land Development Using Multi Criteria Decision Model and Geographical Information System (A Case Study of Babolsar City)." American Journal of Environmental Sciences 5 (1): 87-93. doi:10.3844/ajessp.2009.87.93.

Madanipour, A. 2006. "Roles and Challenges of Urban Design." Journal of Urban Design 11 (2): 173193. https://doi.org/10.1080/13574800600644035

Map, O. S. 2019. “Open Street Map Data Extracts." Open Street Map, August 22. https://download. geofabrik.de/index.html

McBurney, T. 2009. Gulu Masterplan: Sustainable Urbanism through Reinterpreted Traditional Housing Typology. Bathurst: Integrated Design Group. 
McHarg, I. 1992. Design with nature. New York: John Wiley \& Sons. Originally published in 1969.

Muchadenyika, D., and J. Waiswa. 2018. "Policy, Politics and Leadership in Slum Upgrading: A Comparative Analysis of Harare and Kampala." Cities 82: 58-67. doi:10.1016/j.cities.2018.05.005.

Mukwaya, P., P. Wegulo, D. Tugume, P. Kasaija, and D. Pozhidaev. 2018. Urban Public Space and Land Management: Local Assessment for Equitable Growth in Gulu and Mbale Municipalities, Uganda. Brussels: Cities Alliance, United Kingdom Aid, United Nations Capital Development Fund.

Mutuku, B., L. Boerboom, and A. M. Madureira. 2019. "The Role of Planning Support Systems in National Policy Transfer and Policy Translation in Secondary Cities." International Planning Studies 24 (3-4): 293-307. doi:10.1080/13563475.2019.1657809.

Myagmartseren, P., M. Buyandelger, and S. Anders Brandt. 2017. "Implications of a Spatial Multicriteria Decision Analysis for Urban Development in Ulaanbaatar, Mongolia." Mathematical Problems in Engineering 2017: 1-16. doi:10.1155/2017/2819795.

Omolo-Okalebo, F. 2011. "The Evolution of Town Planning Ideas, Plans and Their Implementation in Kampala City 1903-2004." KTH Royal Institute of Technology.

Park, S., S. Jeon, S. Kim, and C. Choi. 2011. "Prediction and Comparison of Urban Growth by Land Suitability Index Mapping Using GIS and RS in South Korea." Landscape and Urban Planning 99 (2): 104-114. doi:10.1016/j.landurbplan.2010.09.001.

Pettit, C. J., R. E. Klosterman, P. Delaney, A. L. Whitehead, H. Kujala, A. Bromage, and M. Nino-Ruiz. 2015. "The Online What If? Planning Support System: A Land Suitability Application in Western Australia." Applied Spatial Analysis and Policy 8 (2): 93-112. doi:10.1007/s12061-015-9133-7.

Pieterse, E. 2011. "Grasping the Unknowable: Coming to Grips with African Urbanisms." Social Dynamics 37 (1): 5-23. doi:10.1080/02533952.2011.569994.

Pype, K., S. Van Wolputte, and A. Melice. 2012. "Religion and Transformation within and beyond Africa." Canadian Journal of African Studies 46: 3.

Regional Centre For Mapping Resource For Development. 2018. “Open Data Site." Regional Centre For Mapping Resource For Development, April 22. http://opendata.rcmrd.org/datasets/uganda-sitm-dem-30-meters

Saaty, T. L. 2008. "Decision Making with the Analytic Hierarchy Process." International Journal of Services Sciences 1 (1): 83-98. doi:10.1504/IJSSCI.2008.017590.

Steen, M., M. Manschot, and N. De Koning. 2011. "Benefits of Co-design in Service Design Projects." International Journal of Design 5: 2.

Terreni Brown, S. E. 2013. "Kampala's Shitscape: Exploring Urbanity and Sanitation in Uganda." Unpublished PhD Thesis. Edinburgh: University of Edinburgh.

United Nations Habitat, and Ministry of Lands Housing and Urban Development. 2016. Towards Achieving SDG 11 in Uganda: Making Cities and Human Settlements Inclusive, Liveable, Safe, Resilient, Productive and Sustainable. New York: United Nations.

Valente, A. 2017. "A City for Who?". Pambazuka News, June 10. https://www.pambazuka.org

Van Noorloos, F., and M. Kloosterboer. 2017. "Africa's New Cities: The Contested Future of Urbanisation." Urban Studies 55 (6): 1-19.

Vokes, R. 2019. "Signs of Development: Photographic Futurism and the Politics of Affect in Uganda." Africa 89 (2): 303-322. doi:10.1017/S0001972019000081.

Wang, Y., C. Jin, L. Mengqiu, and L. Yuqi. 2017. "Assessing the Suitability of Regional Human Settlements Environment from A Different Preferences Perspective: A Case Study of Zhejiang Province, China." Habitat International 70: 1-12. doi:10.1016/j.habitatint.2017.09.010.

Watson, V. 2014. "African Urban Fantasies: Dreams or Nightmares?" Environment and Urbanization 26 (1): 215-231. doi:10.1177/0956247813513705.

Wekwete, K. H. 1995. "Planning Law in Sub-Saharan Africa-A Focus on the Experiences in Southern and Eastern Africa." Habitat International 19 (1): 13-28. doi:10.1016/0197-3975(94)00051-3.

Weller, R. 2009. Boomtown 2050. Perth: University of Western Australia Press.

Zhang, X., C. Fang, Z. Wang, and M. Haitao. 2013. “Urban Construction Land Suitability Evaluation Based on Improved Multi-criteria Evaluation Based on GIS (MCE-GIS): Case of New Hefei City, China." Chinese Geographical Science 23 (6): 740-753. doi:10.1007/s11769-013-0609-6. 